\title{
A INFLUÊNCIA DA LÍNGUA MATERNA EM AULAS DE LÍNGUA INGLESA DE UMA ESCOLA DE IDIOMAS: UM ESTUDO DE CASO
}

\author{
Kaline Brasil Pereira Nascimento* \\ Sinara de Oliveira Branco **
}

\begin{abstract}
Resumo: Considerando as afirmações de Bakhtin (2006), a língua materna (LM) representa para o sujeito familiaridade, de forma que a palavra na língua nativa é vista como um irmão. A relação sujeito-LM está presente no contexto de ensino de língua estrangeira (LE), no entanto, é relevante que esse uso seja discutido. Sendo assim, este trabalho objetiva investigar a frequência do uso de LM por parte da professora de uma turma de língua inglesa de uma escola de idiomas, em Campina Grande-PB e analisar a (in)adequação desse uso. Para tanto, foram observadas e gravadas 9 aulas e utilizadas notas de campo; além de entrevista com a professora da turma. Observou-se que a LM foi utilizada nas aulas de LE, por parte da professora, no início das aulas, durante brincadeiras e durante atividades de leitura e escrita, revelando a influência da LM em sala de LE mesmo que esse uso seja negado pela professora, reforçando a afirmação de Bakhtin sobre a relação do sujeito com sua LM. Palavras-chave: Ensino. Língua estrangeira. Língua materna. Ferramenta pedagógica.
\end{abstract}

\begin{abstract}
Bakhtin (2006) affirms that the mother tongue represents familiarity to the subject in a way that the native word is considered a sibling. The relationship subject-mother tongue is present in the context of teaching a foreign language (FL). This presence makes the discussion about the use of the mother tongue in FL teaching relevant. Therefore, this paper aims at investigating the frequency of the use of the mother tongue by the teacher of an English language group of a language school, in Campina Grande-PB as well as at analyzing the (in)appropriateness of this use. In order to achieve such aims, 9 classes were observed and recorded, field notes were taken, and an interview was done with the teacher of the group. It was observed that the mother tongue was used by the teacher during the classes at the beginning of the classes, during games and during reading and writing activities, showing that the mother tongue has an influence in FL classes even when such a use was denied by the teacher, reinforcing Bakhtin's idea concerning the relationship between the subject with the mother tongue.
\end{abstract}

Keywords: Teaching. Foreign language. Mother tongue. Pedagogical tool.

\section{LM e LE - Antiga parceira}

A língua materna (LM) está presente em aulas de línguas estrangeiras (LE) desde os primórdios do ensino sistemático de LE, mostrando-se de maneira mais evidente durante o Método Gramática e Tradução - no final do século XVIII - quando as aulas de LE eram ministradas em LM. Entretanto, esse uso foi deixado de lado com o surgimento dos métodos posteriores emergentes, tais como os Métodos Direto, Natural e Audiolingual, com foco maior na comunicação oral e menor em tradução de textos escritos. Ou seja, as ideias subjacentes a tais métodos diziam respeito ao uso exclusivo da LE, não recorrendo ao uso da

\footnotetext{
* Possui Mestrado pelo Programa de Pós-graduação em Linguagem e Ensino, na Universidade Federal de Campina Grande, sob a orientação da Prof $^{\mathrm{a}}$. Dr $^{\mathrm{a}}$. Sinara de Oliveira Branco. Endereço eletrônico: k.aline.brasil@hotmail.com

** Mestrado e Doutorado pelo Programa de Pós-Graduação em Inglês (PGI) na área de Estudos da Tradução da Universidade Federal de Santa Catarina. Professora de Letras/Inglês da Universidade Federal de Campina Grande. Pesquisadora, Coordenadora e Professora do Programa de Pós-Graduação em Linguagem e Ensino da UFCG. Orientadora/Coorientadora de doutorado, mestrado e iniciação científica. Tradutora de artigos científicos.
} 
Tradução ou da LM do estudante (RICHARDS; RODGERS, 1996). Conforme Lucindo (2006), a LM passou a ser considerada vilã do desenvolvimento da LE, visão ainda presente, atualmente, no discurso de alguns professores de LE, mesmo com o crescente número de pesquisas que mostram a relação do aprendiz de LE com a sua LM (REVUZ, 1998; PEREIRA, 2001; BAKHTIN, 2006; CORACINI, 2007). Entendemos que o olhar negativo de alguns professores com relação à presença da LM no contexto de sala de aula de LE pode advir de desconhecimento ou desconsideração da LM como parte constituinte do sujeito.

Pensando nos argumentos utilizados contra o uso de LM em aulas de LE, alguns questionamentos são pertinentes para essa reflexão: i) Como fazer o aluno não recorrer à LM?; ii) Como levar o aluno a pensar apenas na LE?; iii) Como separar a LE da LM no sistema cognitivo do aluno? Defendemos que as respostas para as três perguntas expostas são de que não é possível dissociar a LM da LE no processo de ensino de LE, uma vez que a relação com a LM os constitui como sujeito, como afirma Revuz (1998).

Tendo em vista a indissociação do sujeito com sua LM, pretendemos observar a frequência do uso de LM por uma professora de uma turma de língua inglesa como língua estrangeira de uma escola de idiomas da cidade de Campina Grande - PB; e discutir a (in)adequação do uso da LM no contexto mencionado.

\section{Ensino de LE e tradução}

Segundo Richards e Rodgers (1996), durante a Segunda Guerra Mundial, surgiu a necessidade de aprendizagem da LE por parte dos combatentes. De tal necessidade emergiu o Army Method (Método do Exército), caracterizado pelo contato intenso dos aprendizes com a LE. Posteriormente, com a repercussão dos Estados Unidos mundialmente, tornou-se pertinente o ensino da língua inglesa (LI) para os alunos estrangeiros que viajavam para estudar no país. A partir de então, surgiu o audiolingualismo, em meados de 1950, cujos princípios basilares eram: a) foco principal na oralidade; b) foco na estrutura, sendo a repetição e memorização de estruturas fatores fundamentais para o sucesso do ensino da LE; c) variante nativa como referência de pronúncia 'correta'; d) uso permanente da LE em sala de aula, sendo o uso da LM e de tradução 'desencorajados' (RICHARDS; RODGERS, 1996, p. 51).

De acordo com Richards e Rodgers (Ibid), o Método Audiolingual é baseado no pressuposto de que a língua é um conjunto de hábitos, de forma que o aluno precisa ser exposto a condicionamentos através de um processo mecânico de estímulo-resposta, processo esse defendido pela Psicologia Behaviorista. No caso do contexto de ensino de uma LE, sempre que os aprendizes utilizarem a estrutura da língua corretamente, o professor precisa reforçar, através de um elogio, por exemplo, a fim de que o aluno seja motivado a repetir, memorizar, correspondendo ao estímulo causado.

Nesse sentido, ao professor é cabido o papel de 'depositar' nos aprendizes o conhecimento e provocar neles o estímulo. Aos aprendizes, por sua vez, fica o papel de receber o conhecimento transmitido pelo professor, repetir, memorizar e corresponder ao estímulo causado. Esse estilo de ensino é classificado por Scrivener (1994) como jug and mug, ou seja, "jarro e caneca", em que o conhecimento é depositado em um recipiente anteriormente vazio. Para Freire (1987, p. 33), trata-se de uma educação "bancária", por lembrar justamente o depósito bancário, que no âmbito de sala de aula, é feito pelo professor no aluno, como se este não fosse capaz de expor seus conhecimentos anteriores, unindo-os aos conhecimentos novos e assim estando em construção constante. 
As ideias que subjazem ao Método Audiolingual apontam para a repetição e memorização de estruturas como maneiras cruciais para o aprendizado da LE. Nesse sentido, a recorrência à LM é considerada desnecessária e prejudicial ao desenvolvimento da LE, devendo ser evitada, 'banida' da sala de aula. Todavia, entende-se que o domínio das estruturas de um código linguístico não é suficiente para uma comunicação efetiva. Um momento de comunicação pode ser 'quebrado' devido ao uso mais ou menos formal da língua, desconhecido por um dos participantes da comunicação, bem como devido ao uso de gírias, de expressões próprias de uma área específica (jornalismo, medicina, música, etc.), ou ainda pelo não domínio do tópico da conversação. Concordamos com Souza (1999), ao afirmar que quanto mais o foco é dado ao nível sintático da língua, mais artificial ela se torna. Embora o autor esteja tratando do uso da tradução como ferramenta pedagógica, entende-se que tal assertiva vale para o ensino de LE, de forma geral.

Conforme as ideias defendidas pelo audiolingualismo, o ensino de LE deveria dar-se exclusivamente na LE, não havendo interferência da LM do aluno. Esse posicionamento apoia-se no argumento de que o uso da LM em aulas de LE faz com que os aprendizes queiram usar estruturas da LE como se fossem de LM. Como afirma Pereira (2001), é comum ouvir de professores de LE que é necessário 'esquecer' a LM, a fim de pensar apenas na LE. Entretanto, entende-se que não há como 'desativar' e 'ativar' a LM, visto que é inerente ao sujeito, língua na/pela qual o sujeito se constitui, a língua do familiar, do conhecido, como afirma Revuz (1998). Considerando que a LM é uma língua presente na vida do aluno desde sua infância, está também presente na sala de aula de LE, mesmo em meio à relutância e resistência por parte de muitos professores, como é discutido no tópico que segue.

\subsection{Papel da LM no processo de ensino de LE}

Não sinto o mesmo gosto nas palavras:/ oiseau e pássaro./ Embora elas tenham o mesmo sentido./ Será pelo gosto que vem de mãe? de língua mãe?/ Seria porque eu não tenha amor pela língua/ de Flaubert?/ Mas eu tenho./ (Faço este registro/ porque tenho a estupefação/ de não sentir com a mesma riqueza as/ palavras oiseau e pássaro)/ Penso que seja porque a palavra pássaro em/ mim repercute a infância/ E oiseau não repercute./ Penso que a palavra pássaro carrega até hoje/ nela o menino que ia de tarde pra/ debaixo das árvores a ouvir os pássaros./ Nas folhas daquelas árvores não tinha oiseau/ Só tinha pássaros./ É o que me ocorre sobre língua mãe.

(Manoel de Barros)

No poema citado, Manoel de Barros trata da relação do sujeito com sua LM, sendo construída desde a infância de cada sujeito. No contexto de ensino-aprendizagem de LE, pensar sobre a conexão sujeito-LM implica refletir acerca da complexidade inerente ao processo de aprendizagem de uma LE. Se, por um lado, a LM representa para o aluno o conforto, o apoio, o familiar, aquilo que está próximo, por outro lado, a LE representa a língua do 'estranho', a língua do outro, a língua do não familiar (DE NARDI, 2005).

São essas representações que fazem com que o contato com a LE provoque, segundo Revuz (1998), uma desestabilização dos aspectos aparentemente fixos e estáveis da LM. É quando o sujeito passa a olhar e enxergar a si mesmo, a refletir sobre sua língua, ou seja, é o reencontro com sua LM, que é diferente da LE, em alguns aspectos, ao passo que converge, em outros. Trata-se de um processo complexo, em que cada aluno, enquanto sujeito, vivencia diferentes experiências e reações frente ao desafio de se familiarizar com o estranho. Segundo Coracini (2007), há aprendizes, que, quando em contato com a LE, mostram-se resistentes e 
relutantes. Entendemos que a razão dessa ocorrência vai além do (não) domínio do código linguístico em si, dizendo respeito ao relacionamento que cada sujeito constrói com sua LM, e consequentemente com tudo aquilo por que perpassa a LM.

Considerando-se a pertinência da LM para o sujeito, entende-se que a tentativa de 'apagamento' dessa língua é apenas ilusória, de forma que, tentar 'banir' a LM das aulas de LE é também tentar banir parte do sujeito. Sendo assim, é válida a reflexão acerca do papel da LM nas aulas de LE. Segundo Harbord (1992, apud CANTAROTTI, 2007, p. 22), uma das possibilidades de uso de LM em aulas de LE é "permitir que o aluno diga algo que realmente quer dizer, para que o professor possa ajudá-lo a achar o meio adequado de transmitir a mesma mensagem na LE." Em aulas de LE, há situações em que o aluno, por mais esforçado e dedicado que seja, apresenta dificuldades na construção da ideia, na LE, não transmitindo a mensagem desejada e, algumas vezes, acabando por transmitir sua mensagem ou parte dela em LM. Nesse caso, a recorrência à LM possibilita a compreensão da mensagem, por parte do/a professor/a da turma, podendo auxiliar o aluno na transmissão da mensagem em LE.

Assim, acredita-se que a recorrência à LM pode auxiliar o/a professor/a no diagnóstico das dificuldades dos aprendizes, para assim trabalhar pontos específicos da LE. Dessa maneira, o auxílio do/a professor/a pode contribuir para a compreensão, por parte do aluno, de que não há relação plena e unívoca entre as palavras em LM e LE, distanciando-se, assim, da tradução palavra-por-palavra.

Segundo Ellis (1997), a LM pode ser utilizada para o ensino de estruturas da LE que não têm equivalentes na LM, como no caso do tempo verbal present perfect, utilizado com frequência na língua inglesa, enquanto em português utiliza-se o tempo passado simples. No sentido de mostrar especificidades da LE, a comparação com a LM do aluno colabora para o processo de percepção de que as línguas não têm relação plena, sendo este um momento imprescindível durante o processo de ensino-aprendizagem de LE, segundo Revuz (1998), visto que se estilhaça a ilusão de possível tradução termo-a-termo. Nesse sentido, a LM é usada em um processo de metalinguagem, ou seja, discussões, explicações acerca do funcionamento da língua.

O uso da LM é viável, também, durante a explicação de expressões idiomáticas, a fim de mostrar aos aprendizes que traduzir literalmente a expressão gera compreensão equivocada do seu significado. Por exemplo, no contexto de ensino de língua inglesa para aprendizes brasileiros, traduzir a expressão "The early bird catches the worm", como "O pássaro que acorda cedo caça a minhoca" não é familiar em LM, visto que as expressões se constroem dentro de contextos específicos. Nesse sentido, é relevante que os aprendizes sejam levados à compreensão do significado da expressão, como um todo, em LE, para posteriormente identificar a expressão que tem o mesmo sentido em LM, no caso da expressão mencionada: "Deus ajuda a quem cedo madruga". Utilizada dessa forma, a LM funciona como ferramenta para guiar os aprendizes à compreensão do sentido de expressões na LE.

\section{Observando a LM em aulas de LE: da teoria à prática}

A observação desenvolvida para o alcance dos objetivos apresentados segue caráter etnográfico, de cunho quanti-qualitativo. Segundo Moreira e Caleffe (2008), o estudo de base etnográfica é um trabalho de campo que envolve a presença do pesquisador de forma mais natural possível no ambiente da pesquisa, investigando os participantes, suas ações, suas atividades, suas experiências. 
O objetivo inicial apresentado propõe investigar a frequência de uso da LM pela professora em aulas de língua inglesa de uma escola de idiomas. Entretanto, os números obtidos não são suficientes para responder à observação da (in)adequação do uso da LM durante as aulas de língua inglesa, sendo necessário o desenvolvimento de um estudo qualitativo, que, segundo Williams e Chesterman (2010), descreve a qualidade dos dados de forma esclarecedora, elucidativa.

A coleta de dados foi realizada em uma turma do $4^{\circ}$ estágio, nível intermediário (segundo a divisão estabelecida pela escola) de uma escola de idiomas, da cidade de Campina Grande - PB. Os recursos utilizados pelo professor são comuns em todas as salas de aula da escola: TV, DVD, quadro branco e Livro do Professor (LP). Além disso, a maioria das salas de aula também é provida de câmeras. Quando a coleta de dados foi iniciada, a turma estava em uma sala de aula em que ainda não havia câmeras. Todavia, as 3 últimas aulas foram ministradas em outra sala, provida de câmeras. A mudança ocorreu devido a uma reforma na sala. Essa ocorrência parece ter provocado uma mudança na prática pedagógica da professora da turma, como será apresentado nos resultados da pesquisa.

Para preparação das aulas, cada professor permaneceu com o LP, devolvendo-o à escola apenas ao final do semestre. Cada aluno, por sua vez, possuía um conjunto de 03 livros (1 livro de leitura e gramática, 1 livro de prática auditiva e 1 livro de atividades) e $01 \mathrm{CD}$. Na turma observada, havia 10 aprendizes, com idades variadas, entre 13 e 26 anos.

A professora da turma (P1) afirmou ter concluído seu curso de graduação em LetrasLicenciatura com habilitação em Língua Inglesa em 2012. De forma geral, ela leciona LE há três anos, naquela instituição. As experiências anteriores de ensino de LE ocorreram durante a graduação, na disciplina Estágio Supervisionado. Sendo assim, sua experiência enquanto professora envolve basicamente o contexto de escola de idiomas. Acerca do uso de LM em aulas de LE, P1 assume o seguinte posicionamento:

Eu não acho que seja uma boa ideia, porque interfere na aprendizagem da língua estrangeira... Porque senão eles podem acabar entendendo o que eu estou falando em inglês, mas não vão conseguir falar em inglês, só vão querer falar em português, né? E não é uma boa, porque tem uma interferência da língua materna na língua estrangeira. Então se eles estão ali pra aprender inglês, então eles têm que fazer por onde, procurar se esforçar, falar em inglês. (ênfase nossa)

A fala de P1, em negrito, demonstra sua visão acerca da recorrência à LM como falta de esforço. Essa afirmação é reforçada em outro momento da entrevista, quando diz que: "Se a aula é de inglês, então tem que ser inglês. Não pode ser inglês-português. A aula toda em inglês é o certo." As ideias defendidas por P1 mostram sua visão de que o uso da LM em alguns momentos da aula, por parte dos aprendizes, ocorre devido à falta de esforço, por parte dos mesmos, em se expressar a LE. A partir da afirmação de P1 é possível atestar as palavras de Coracini (2007), na afirmação de que é comum entre professores de LE a visão dicotômica de LE-LM, ignorando o fato de que essas línguas se interpenetram quando o sujeito entra em contato com a LE.

As palavras de P1 ainda demonstram sua visão acerca de domínio da língua como sendo domínio de estruturas, pois, segundo ela, se os aprendizes já têm certas estruturas internalizadas em LE, não há razão para recorrer à LM. Dessa maneira, P1 parece não considerar a importância e a relação de afeto estabelecida entre os aprendizes e sua LM, não considerando também o conforto que a expressão em LM possibilita. Tal relação do sujeito com a LM pode ser constatada durante a prática pedagógica de P1, uma vez que sua 
resistência, no que tange à presença de LM nas aulas de LE, contradiz sua prática pedagógica, como será exposto nos resultados da pesquisa.

Um dos instrumentos utilizados durante a coleta de dados foi a gravação em áudio. Para esse procedimento, utilizou-se um gravador digital, para uma melhor captação do som, facilitando a análise dos dados, posteriormente. Foram gravadas 9 aulas com duração de 1 hora e 30 minutos cada, somando 13 horas e 30 minutos de aula.

Além das gravações em áudio, foram utilizadas notas de campo, que serviram para coletar dados que não poderiam ser captados pelo áudio, tais como gestos, expressões faciais, encenações, alguma fala muito baixa. Por fim, foi realizada uma entrevista com a professora da turma observada. Embora um roteiro tenha sido previamente planejado, foi possível realizar questionamentos que não haviam sido formulados anteriormente, mas que foram julgados relevantes durante a entrevista.

A seguir, serão apresentados resultados da verificação da frequência de uso da LM em sala de aula de LE e a observação de tal resultado.

\section{Observando o uso da LM em contexto de ensino de LE}

Como está exposto no Gráfico 1, a LM foi utilizada em seis das nove aulas gravadas. Para se chegar ao resultado obtido, quantificamos a recorrência à LM nas aulas, para tanto, consideramos os momentos da aula (leitura, conversação, atividade escrita, etc.) Essa quantificação foi vertida para números percentuais, como apresentado abaixo. Durante essas seis aulas, P1 recorreu à LM 20 vezes. O gráfico mostra como a recorrência ao uso de LM por P1 esteve distribuída nas nove aulas observadas e gravadas.

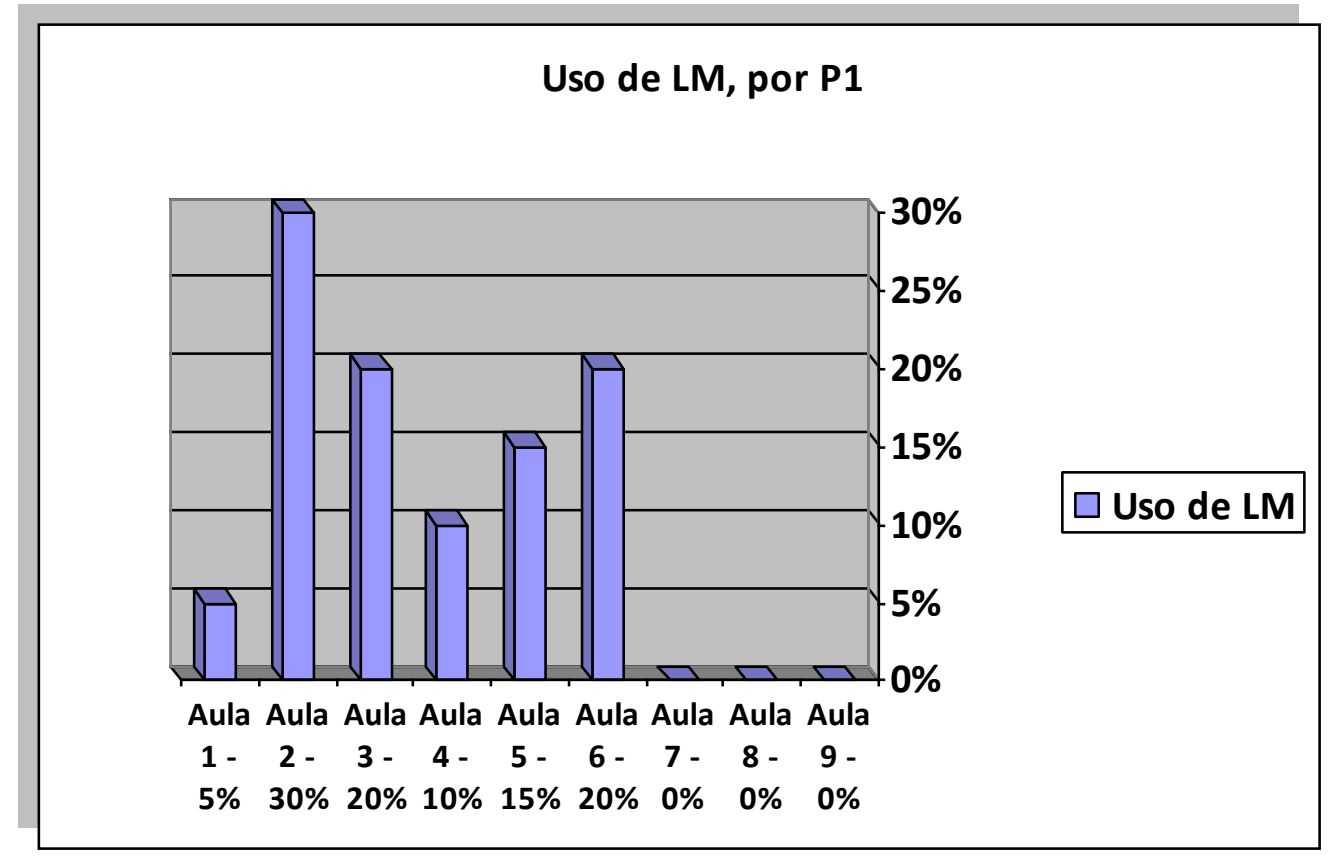

Gráfico 1: Uso de LM, por P1

A recorrência ao uso de LM em sala de aula de LE deu-se em três momentos distintos das aulas, sendo esses: 1) no início das aulas; 2) durante brincadeiras; 3) em atividades de leitura e escrita. 
No Trecho 1, a intenção de uso de LM no início da aula foi informativa, sobre atividades escritas. P1 interage com a turma, fornecendo respostas também em LM.

\section{Trecho 1}

$\mathrm{A} 1^{1}$ : Tu enviou (sic) a atividade, $\mathrm{P} 1$ ?

P1: Eu tentei enviar os e-mails pra vocês

$\mathrm{A} 1$ : Tu tem (sic) internet?

P1: Tenho, eu tentei enviar, mas a minha internet não tá boa. É via rádio. (risos)

[...]

P1(risos): Ok, Let's begin!

O uso da LM foi comum no início das aulas. A indicação de que a LE começaria a ser utilizada era marcada pela frase "Let’s begin!" ("Vamos começar!"), por parte de P1, como no exemplo supracitado. Esses e outros momentos de uso da LM reforçam a relação de afetividade estabelecida entre o sujeito e sua língua materna, da qual trata Bakhtin (2006), ao mencionar que a LM é a língua que representa o familiar. O uso de LM por parte de P1 é incoerente com o seu depoimento durante a entrevista, ao afirmar que a recorrência à LM se restringe à falta de esforço.

P1 também interage em LM, com os aprendizes, ao corresponder às brincadeiras. No Trecho 2, por exemplo, P1 ainda não havia iniciado o conteúdo em si, apenas preenchia a lista de chamada, quando A1 fez um comentário em LM, correspondido por P1 também em LM:

Trecho 2

P1 (risos): O bichinho, ficou com pena de mim.

$\mathrm{A} 1$ : Mas também, $\mathrm{A} 4$, não tem condições não, $\mathrm{P} 1$ tava escrevendo com um lápis desse tamanho aqui, ó. Eu digo, não, tome esse aqui.

(risos)

P1 (pega o lápis) Olha, da Faber Castel, óóóó!

(risos)

O uso de LM gerando momentos de descontração em sala de aula foi comum, ora iniciado pelos aprendizes da turma, ora por parte de P1. Embora o uso da LM, nos trechos mencionados não tenha sido pedagogicamente planejado (pois a professora afirmou, durante a entrevista, não utilizar a LM em sala de aula, por não concordar com esse uso), compreendese que essa recorrência deu-se devido à familiarização com sua LM, de forma que tecer as brincadeiras e comentários feitos em LM, em LE, não traria o mesmo resultado - entreter, rir.

Diferentemente do que P1 afirmou em seus depoimentos, a LM está, sim, presente em suas aulas de LE. A partir das afirmações de Pereira (2001) acerca da afetividade que a LM carrega, entende-se que a recorrência à LM não se restringiu à questão de preguiça ou falta de esforço, como afirmou P1, durante a entrevista. Explicar a presença da LM em aulas de LE como questão de falta de esforço implicaria dizer que a falta de esforço também se deu por parte de P1. Não obstante, considerando as afirmações de Revuz (1998), de Pereira (2001), de Coracini (2007), o sujeito se identifica com a LM, devido à relação que foi construída com essa língua, desde a infância, de forma que não há como simplesmente 'apagá-la', em prol do aprendizado de uma LE.

A relação do sujeito com sua LM é marcada no poema $A$ língua mãe, de Manoel de Barros, transcrito no ponto 2.2 deste trabalho, em cujo poema o autor fala do significado que

\footnotetext{
${ }^{1}$ Os nomes dos aprendizes não serão mencionados, por questões de sigilo. Dessa forma, eles serão mencionados como aluno 1, aluno 2, aluno 3, etc., cuja abreviação no texto é A1, A2, A3, etc.
} 
carrega a palavra 'pássaro' que não está presente na palavra 'oiseau' ('pássaro', em francês). Para o autor, as palavras da LE não carregam o mesmo significado para o sujeito que as palavras em LM. Mais do que um código linguístico familiar, a LM faz parte de uma historicidade vivenciada, é a língua de descoberta do mundo a sua volta, a língua da mãe. Sendo assim, entende-se que há um conforto da parte do aluno e do professor em utilizar a sua LM em momentos de descontração, ao se tecer uma brincadeira, por exemplo.

Um dado curioso, que pode ser visto no Gráf. 1, diz respeito à discrepância de uso de LM nas três últimas aulas, por parte de $\mathrm{P} 1$, quando comparado às aulas anteriores. Enquanto nas 6 primeiras aulas, P1 recorreu à LM em uma porcentagem entre 5\% e 30\%, nas 3 últimas aulas, essa porcentagem caiu significativamente para $0 \%$. As 3 últimas aulas coincidem com a mudança de sala de aula, mencionada no item 3 deste trabalho.

Como mencionam Swan e Walter (1990, apud PEREIRA, 2001), há casos em que a instituição de ensino não permite a utilização da LM em sala de aula de LE, como é o caso da instituição onde ocorreu a coleta de dados. Inicialmente, P1 recorria à LM em alguns momentos da aula. No entanto, com a presença das câmeras, P1 passou a não utilizar a LM em nenhum momento das aulas, bem como não permitiu que os aprendizes o fizessem, demonstrando irritação e desconforto com o uso de LM. A partir da mudança radical de postura por parte de P1, é possível conjecturar que P1 nega o uso da LM em sala de aula, por repetir, de forma não reflexiva, o discurso pregado pela escola de que a presença da LM prejudica o desenvolvimento da LE.

Além disso, é importante mencionar que a escola utiliza o método audiolingual, que defende o aprendizado da LE dentro na própria LE, não recorrendo à LM. Essa ideia desconsidera a existência de uma língua inerente ao aluno, constituindo-o enquanto sujeito. Pensar na necessidade de esquecimento da LM durante o aprendizado da LE é também acreditar na possibilidade de um sujeito que controle plenamente seus pensamentos, de forma a ora acionar, ora desativar uma língua, mecanicismo este que não se concretiza em sala de aula, visto tratar-se de seres humanos em constante processo de transformação.

Radicalmente diferente no ocorrido nas últimas, na aula 2, P1 fez uso da LM com uma porcentagem de $30 \%$. Esse dia foi referente a uma aula da sexta-feira, em que vários estudantes faltaram, e nem todas as turmas da escola funcionaram, pois a aula desse dia da semana contava, na maioria das vezes, com poucos aprendizes, por ser considerada uma aula 'extra'. Essa aula foi voltada especificamente para atividades escritas. Os participantes da pesquisa pediam a ajuda de P1 quando necessário. Durante a aula, eles conversavam uns com os outros em LM, o que não provocou qualquer irritação em P1, que também utilizou a LM para responder às perguntas, bem como em conversas paralelas. Nesse sentido, entende-se que a recorrência à $\mathrm{LM}$ tenha sido equivocada, pois além de não estar pautada em objetivos pedagógicos claros, P1 não controlou esse uso, permitindo que a comunicação fosse toda em LM, nessa aula.

Assim como a permissão da LM nessa aula foi equivocada, alguns momentos de bloqueio de uso da LM também foram equivocados, como no trecho que segue.

Trecho 3

P1: Are you tired?

A2: So-so. I'm freedom now!

P1: Ãh?

A2: I'm freedom now...

P1 (demonstra não compreender)

A2: Tô livre

P1: Aham, aham, aham, ok, great! (demonstrando irritação e impaciência) 
Em vez de "I'm free" (Estou livre), A2 expressa "I'm freedom". Há um equívoco na frase, não de ordem gramatical, mas de ordem lexical, uma vez que "free", na frase, remete ao adjetivo "livre", enquanto "freedom" remete ao substantivo "liberdade". Mesmo após a repetição da resposta duas vezes, P1 não compreendeu a resposta de A2. A dificuldade de compreensão de $\mathrm{P} 1$ deu-se, a nosso ver, devido à dificuldade de pronúncia de $\mathrm{A} 2$, não pela troca do adjetivo pelo substantivo em si. Percebendo a não compreensão da professora, o aluno optou por responder em língua portuguesa. Considerando as afirmações de Harbord (1992, apud CANTAROTTI, 2007), o uso da LM, por parte de A2, constituiu uma oportunidade para que a professora diagnosticasse a(s) dificuldade(s) do aluno, com vistas a corrigi-las e levar o aluno à prática da LE. Não obstante, através da imposição de vozes, a professora pareceu ter tentado evitar o uso de tradução, quando euforicamente afirmou ter entendido a resposta de A2, de forma que o erro linguístico na frase de A2 não foi corrigido, a LE não foi trabalhada, explorada, e a dificuldade foi ignorada, quando P1 disse: "Ok, great!" (Ok. Ótimo!).

No Trecho 4, A2, mais uma vez, não consegue formular sua resposta em LE:

Trecho 4

P1: Did you build sandcastles when you were a kid?

A2: No, I didn't build

P1: Why?

A2: I not... I don't... I no... Eu não sei fazer um

P1: OH, ENGLISH. OH, A2. A2! (demonstra irritação/desconforto)

A2: Sorry!

P1: I don't know how to do sandcastle.

A2: Yes!

P: Ok! Ok! Ok!

No exemplo citado, A2 não conseguiu formular a resposta desejada, recorrendo então à LM, a fim de expressar sua ideia. P1, por sua vez, demonstrou desconforto e irritação com esse uso, de forma que antes que A2 concluísse a resposta em LM, houve a imposição de voz, por parte de P1, quando disse: "OH, ENGLISH. OH, A2. A2!". Nesse momento, A2 se desculpa pelo uso de LM e P1 traduz para LE a frase iniciada por A2, em LM.

O Trecho 4 apresenta uma situação complexa para A2. Por um lado, a LE representa o desafio, o espaço estranho, em que A2 não conseguiu se expressar. Por outro lado, a LM representa a língua do familiar, do próximo, mas à qual 'não se pode' recorrer. Vale salientar que A2 apresentou dificuldades durante as aulas de LE, apesar do esforço e da dedicação para com o curso. Essa ocorrência diz respeito ao fato de que cada sujeito reage e comporta-se diferentemente ao entrar em contato com uma LE (cf. CORACINI, 2007).

A partir dos dados expostos, serão apresentadas, a seguir, as considerações finais da pesquisa.

\section{LM e LE - Indissociáveis}

O presente estudo se propôs a responder aos seguintes questionamentos: 1) qual a frequência do uso de LM em uma turma de língua inglesa de uma escola de idiomas, da cidade de Campina Grande - PB? e 2) o uso de LM ocorreu adequadamente no contexto em foco?

Como apresentado abaixo, durante as nove aulas observadas, a professora da turma recorreu à LM com as seguintes porcentagens: 


\begin{tabular}{|c|c|c|c|c|c|c|c|c|}
\hline Aula 1 & Aula 2 & Aula 3 & Aula 4 & Aula 5 & Aula 6 & Aula 7 & Aula 8 & Aula 9 \\
\hline $5 \%$ & $30 \%$ & $20 \%$ & $10 \%$ & $15 \%$ & $20 \%$ & $0 \%$ & $0 \%$ & $0 \%$ \\
\hline
\end{tabular}

Quadro 1: Porcentagem de uso da LM, por P1

O uso de LM deu-se nos seguintes momentos: 1) início das aulas; 2) durante brincadeiras; e 3) atividades de leitura e escrita.

O uso da LM no início das aulas, bem como durante brincadeiras e para explicação de pronúncia, teve por objetivo informar, entreter, descontrair - momentos pontuais da aula. Nesse sentido, não entendemos que exista inadequação nessas recorrências à LM. Embora o objetivo do uso da LM, por parte de P1, não tenha sido pedagogicamente planejado (considerando seus depoimentos durante a entrevista), o uso da LM nos três momentos aqui mencionados foi pontual, controlado, dosado, de forma que, rapidamente após a brincadeira ou a informação em LM, a professora guiou a aula à LE, com frases do tipo "Ok. Let's go!" (Ok. Vamos continuar!), dando prosseguimento à aula. Esses resultados mostram a indissociação da LE e da LM, da qual trata Coracini (2007), no sentido de que o aprendiz de LE passa a ser sujeito tanto da LM quanto da LE, estando inserido em um processo de familiarização com a LE (cf. REVUZ, 1998).

No que diz respeito às inadequações, registrou-se que, em momentos de atividades de leitura e escrita, P1 recorreu ao uso da LM de forma indiscriminada, não dosada, de forma que a recorrência à LM passou a ser mais constante do que a recorrência à LE, tanto por parte dos aprendizes, quanto por parte de P1, na aula específica de atividades escritas. Dessa forma, P1 acabou por desconsiderar o objetivo de ensino de LE do contexto em foco, que é expor o aluno à prática oral da LE.

Além disso, houve também inadequações em momentos de coibição do uso de LM, que se deu especialmente após a mudança de sala de aula. Nesses momentos, o foco de P1 estava em não permitir o uso de LM, ignorando um direcionamento para as dificuldades dos aprendizes, especialmente de A2, que demonstrava dificuldade mais acentuada do que os outros aprendizes da turma. Entendemos que a recorrência à LM, por parte do aluno, após várias tentativas, sem êxito, de se expressar em LE, proporcionou à P1 uma oportunidade de compreender a mensagem de A2 em LE. A identificação da mensagem do aluno, a partir do que o mesmo expôs em LM, possibilita, segundo Harbord (1992, apud CANTAROTTI, 2007, p. 22), o diagnóstico de possíveis problemas do aluno, de ordem fonológica, morfológica, sintática, vocabular. Não obstante, P1 ignorou esses momentos, que foram complexos para A2, pois as várias tentativas de falar em LE provocaram não compreensão, por parte de P1. A tentativa de se expressar em LM tinha como resultado reclamações por parte de P1, a ponto de A2 precisar se desculpar pelo uso de LM. As tentativas de expressão em LM de A2 eram finalizados com falas de P1, tais como: “Ah, ok, ok! Great!" (Ah, ok, ok! Ótimo), que, a nosso ver, demonstraram certo descaso com as limitações e dificuldades do aluno.

Nesse sentido, percebemos que a LM está presente em sala de aula de LE independentemente da (não)permissividade, pois a LM é parte da vida da professora, bem como dos aprendizes. Por isso, entendemos ser mais proveitoso repensar o como do uso da LM, para que essa recorrência se dê de forma equilibrada, em momentos pontuais da aula e com objetivos refletidos, quer mostrar uma especificidade da língua, quer contrastar algum aspecto importante da LE e a LM - de maneira metalinguística - ou até mesmo para um momento de descontração. Por isso, é imprescindível que essa língua, intrínseca ao aluno, seja aproveitada de forma positiva, com objetivos claros, pensando no sujeito e na sua relação com 
a LM, bem como no foco da aula: aprendizagem e desenvolvimento da LE. O uso da LM pode ser gerenciado, focado, mas não 'apagado'.

\section{Referências}

BAKHTIN, M. Língua, Fala e Enunciação. In: Marxismo e Filosofia da Linguagem. 12ed. 2006.

BARROS, M. A Língua mãe. Disponível em <http://www.bloghetto.com.br/2009/07/euassinaria-embaixo2/> Acesso em 03/02/2012.

CANTAROTTI, A. A Língua Materna em sala de aula de Língua Estrangeira: O recurso da alternância de código na fala de uma professora e o desenvolvimento da Interlíngua de alunos em um curso de Secretariado Executivo. 2007. 250 fls. Dissertação (Mestrado) - Programa de Pós-Graduação em Estudos da Linguagem, Universidade Estadual de Londrina, Londrina.

CORACINI, M. J. Língua materna-estrangeira: entre saber e conhecer. In: . A celebração do outro: arquivo, memória e identidade: línguas (materna e estrangeira), plurilinguismo e tradução. Campinas: Mercado de Letras, 2007, p. 149-162.

A estranha relação do sujeito com sua língua materna: algumas reflexões sobre língua e identidade. In: MITTMAN, S.; GRIGOLETTO, E.; CAZARIN, E. Práticas discursivas e identitárias: sujeito e língua. Porto Alegre: Nova Prova, 2008.

DE NARDI, F. S. A estranha relação do sujeito com a língua materna: algumas reflexões sobre língua e identidade. In: MITTMANN, S.; GRIGOLETTO, E.; CAZARIN, E. A. (Orgs.). Práticas discursivas e identitárias. Ensaios PPG Letras UFRGS. Porto Alegre: Nova Prova Editora. 2008.

ELLIS, R. Second Language Acquisition: Oxford introduction to Language Study. Oxford: Oxford University Press, 1997.

FREIRE, P. A Concepção "Bancária" da Educação como Instrumento da Opressão: Seus Pressupostos, Sua Crítica. In: . Pedagogia do Oprimido. 17 ed. Rio de Janeiro: Paz e Terra, 1987.

LUCINDO, E. S. Tradução e Ensino de Línguas Estrangeiras. In: Revista Scientia Tracuctionis. Florianópolis: UFSC, n. 3, 2006, p. 1-11.

MOREIRA, H.; CALEFFE, L. G. Metodologia da Pesquisa para o Professor Pesquisador. Rio de Janeiro: Lamparina, 2008.

PEREIRA, E. F. O. O papel da Língua Materna na aquisição da Língua Estrangeira. Interação, Goiás, v. 26, n. 2, p. 53-62, dez. 2001.

REVUZ, C. A língua estrangeira entre o desejo de um lugar e o risco do exílio. In: SIGNORINI, I. (Org.) Lingua(gem) e Identidade: elementos para a discussão no campo aplicado. Campinas: Mercado de Letras; São Paulo: FADESP, 1998. 
RICHARDS, J. C.; RODGERS, T. S. Approaches and methods in language teaching. Cambridge, Cambridge University Press, 1996.

SCRIVENER, J. Learning Teaching. Oxford: Maemillan Heinemann, 1994, p. 1-8.

SOUZA, J. P. Tradução e Ensino de Línguas. GELNE. v 1, n. 1, p. 141-150, 1999.

WILliAMS, J.; CHESTERMAN, A. The Map: A Beginner's Guide to Doing Research in Translation Studies. UK: St. Jerome, 2010.

Recebido em: janeiro de 2013.

Aprovado em: junho de 2013. 